\title{
Expression and location of HSP60 and HSP10 in the heart tissue of heat-stressed rats
}

\author{
YANFEN CHENG ${ }^{1}$, JIARUI SUN $^{1}$, HONGBO CHEN $^{1}$, ABDELNASIR ADAM $^{1}$, \\ SHU TANG $^{1}$, NICOLE KEMPER ${ }^{2}$, JÖRG HARTUNG ${ }^{2}$ and ENDONG BAO ${ }^{1}$ \\ ${ }^{1}$ College of Veterinary Medicine, Nanjing Agricultural University, Nanjing, Jiangsu 210095, P.R. China; \\ ${ }^{2}$ Institute for Animal Hygiene, Animal Welfare and Farm Animal Behaviour, \\ University of Veterinary Medicine Hannover, Foundation, 30559 Hannover, Germany
}

Received December 12, 2014; Accepted January 11, 2016

DOI: $10.3892 / \mathrm{etm} .2016 .3650$

\begin{abstract}
The present study aimed to analyze the expression levels and localizations of heat shock protein (HSP) 60 and HSP10 in the heart tissue of rats subjected to heat stress $\left(42^{\circ} \mathrm{C}\right)$ for $0,20,80$ and $100 \mathrm{~min}$. Histopathological injuries and increased serum activities of serum lactate dehydrogenase and creatine kinase isoenzyme MB were detected in the heated rat myocardial cells. These results suggested that heat stress-induced acute degeneration may be sufficient to cause sudden death in animals by disrupting the function and permeability of the myocardial cell membrane. In addition, the expression levels of HSP60 were significantly increased following $20 \mathrm{~min}$ heat stress, whereas the expression levels of its cofactor HSP10 were not. Furthermore, the location of HSP60, but not of HSP10, was significantly altered during periods of heat stress. These results suggested that HSP60 in myocardial tissue may be more susceptive to the effects of heat stress as compared with HSP10, and that HSP10 is constitutively expressed in the heart of rats. The expression levels and localizations of HSP60 and HSP10 at the different time points of heat stress were not similar, which suggested that HSP60 and HSP10 may not form a complex in the heart tissue of heat-stressed rats.
\end{abstract}

\section{Introduction}

The exposure of animals to heat stress has previously been associated with increased morbidity and mortality, which in turn have led to substantial economic losses to animal product industries (1). Typically, the increased mortality rate associated

Correspondence to: Professor Endong Bao, College of Veterinary Medicine, Nanjing Agricultural University, 1 Weigang Road, Nanjing, Jiangsu 210095, P.R. China

E-mail: b_endong@njau.edu.cn

Key words: expression, heat stress, heat shock protein 60 , heat shock protein 10 , heart, rats with heat stress is a result of organ failure, particularly heart failure preceded by cardiovascular damage (2).

Heat shock proteins (HSPs), which are ubiquitously expressed and highly conserved in prokaryotes and eukaryotes (3) are classified into families according to their molecular size, including small HSPs, HSP27, HSP40, HSP60, HSP70, HSP90 and HSP110 (4). HSPs are molecular chaperones that have been shown to perform important functions in the folding, unfolding (5) and translocation $(6,7)$ of proteins, in addition to the assembly and disassembly of protein complexes $(8,9)$.

HSP60 and HSP10 are two important chaperones that interact in a two-step folding mechanism in the mitochondria of prokaryotic and eukaryotic cells (10). HSP10 has been reported to be a cofactor involved in HSP60-mediated protein folding and sorting (11). Previous studies investigating HSP60 and HSP10 have focused on their roles in prokaryotic (12) and tumor cells $(13,14)$. In addition, in eukaryotic cells, there have been reports that HSP60 may be involved in angiocardiopathy $(15,16)$. Furthermore, a previous study reported significantly increased levels of HSP60 in the heart tissue, but not in the liver and kidney tissues, of heat-stressed chickens and pigs that have been transported for a long period of time (17). In a previous study, the abnormal trafficking of HSP60 to the cell surface was suggested to be an early trigger for myocyte loss and the progression of heart failure (18). Previous studies have associated HSP10 with numerous cellular processes, including cellular differentiation $(19,20)$, cell proliferation $(21,22)$, cell apoptosis $(23,24)$ and cytoprotection $(25,26)$. Although there is an increasing awareness regarding the protective functions of HSPs, and their importance in numerous regulatory pathways, little is known regarding the expression levels of HSP60 and HSP10 in the heart tissue of mammals under conditions of heat stress. Therefore, the present study aimed to investigate the dynamic expression levels of HSP60 and HSP10, and their associations, in the heart tissue of heat-stressed rats in vivo.

\section{Materials and methods}

Animals and experimental design. A total of 40 adult Sprague-Dawley (SD) rats (20 female and 20 male rats; weight, $220 \mathrm{~g}$ ) were purchased from Qinglong Mountain 
Animal Breeding Ground of the Nanjing Jiangning District (Nanjing, China) for use in the present study. The rats were randomly divided into four groups ( $n=10$ per group). The rats were maintained under standard conditions for 7 days to allow them to acclimatize to their new surroundings and to recover from environmental stress. During this period, the humidity of the chamber was maintained at $60 \pm 10 \%$ and the room temperature was $25 \pm 1^{\circ} \mathrm{C}$. On day 8 , all rats were transferred to a controlled climate chamber (RX8-500D; New Jiangnan, Co., Ltd., Ningbo, China) and exposed to $42 \pm 1^{\circ} \mathrm{C}$ for 0 (control), 20, 80 and $100 \mathrm{~min}$. During the heat stress period, the rats received ad libitum access to feed-stuff and water. The rats were sacrificed by decapitation, after which blood was collected to prepare serum, manually eviscerated and the hearts were rapidly dissected. Half of the heart tissue samples were fixed in $10 \%$ neutral-buffered formalin ( $\mathrm{G}$ fan Biological Technology Co., Ltd., M003, Shanghai, China) for histopathological analyses and the other half was stored in liquid nitrogen $\left(-196^{\circ} \mathrm{C}\right)$ for biological analyses.

The present study was conducted in accordance with the recommendations outlined in the Guide for the Care and Use of Laboratory Animals of the Nanjing Agricultural University (Nanjing, China), and the guidelines of the Animal Ethics Committee of Jiangsu Province (Nanjing, China). The protocol was approved by the Committee on the Ethics of Animal Experiments of Nanjing Agricultural University (permit no. SYXK (su) 2011-0036).

Determination of enzyme activity. The activities of serum lactate dehydrogenase (LDH; A020-2) and creatine kinase isoenzyme MB (CKMB; H197) were determined using commercial kits (Nanjing Jiancheng Biochemical Reagent Co., Nanjing, China) and a clinical autoanalyzer (Vital Scientific NV, Dieren, Netherlands), according to the manufacturer's protocols.

Histopathological analysis. Paraffin-embedded heart tissues that had been fixed in $10 \%$ neutral-buffered formalin were serially sliced into $4-\mu \mathrm{m}$ sections. One of the sections was stained with hematoxylin and eosin (HE; Liansuo Biological Technology Co., Ltd., Shanghai, China), and examined under a light microscope (Axioskop 2 plus; Zeiss GmbH, Jena, Germany).

Immunohistochemical analysis. The heart tissue sections from the heat-stressed and control groups were examined using the streptavidin-biotin-peroxidase complex procedure (85-6643; Invitrogen; Thermo Fisher Scientific, Inc., Waltham, MA, USA). The sections were dewaxed and rehydrated, then incubated with $3 \%$ hydrogen peroxide in methanol for $10 \mathrm{~min}$ in order to inhibit endogenous peroxidases. Subsequently, the tissue sections were placed in $10 \mathrm{mM}$ citric acid buffer ( $\mathrm{pH}$ 6.0), then heated in a microwave oven at $800 \mathrm{~W}$ for $3 \mathrm{~min}$ and $400 \mathrm{~W}$ for $10 \mathrm{~min}$. The sections were incubated with antibodies against HSP60 and HSP10 [1:200 in phosphate-buffered saline (PBS; Wuhan Boster Biological Technology, Ltd., Wuhan, China); polyclonal rabbit HSP10 (ADI-SPA-110; Enzo Life Sciences, Inc., Farmingdale, NY, USA); mouse monoclonal HSP60 (ab5478; Abcam, Cambridge, UK)] overnight at $4^{\circ} \mathrm{C}$. For the negative control, PBS was run instead of the primary antibody. The slices were incubated with a biotinylated secondary mouse antibody from a Histostain-Plus IHC Kit (85-6643; Thermo Fisher Scientific, Inc.) for $20 \mathrm{~min}$ at $37^{\circ} \mathrm{C}$ in a humidified chamber. Subsequently, the tissue sections were washed three times with PBS, incubated for $20 \mathrm{~min}$ in horseradish peroxidase-streptavidin (85-6643; Thermo Fisher Scientific, Inc.), then washed three times with PBS for $5 \mathrm{~min}$ each. Antibody complexes were visualized by incubating the tissue sections with 3-3'-diaminobenzidine (00-2014; Thermo Fisher Scientific, Inc.), after which the tissue sections were incubated with hematoxylin for $30 \mathrm{sec}$ for nuclear counterstaining, followed by mounting. The corresponding negative control sections were prepared by omitting the antibodies.

Western blot analysis. Total protein was extracted from the heart tissues of the rats in the control and heat-stressed groups using ultrasonication (JY99-IIDN; Ningbo New Cheese Instrument Co., Ltd., Ningbo, China) and Radio Immunoprecipitation Assay lysis buffer (Beyotime Institute of Biotechnology, Nanjing, China), and protein concentrations were determined using the bicinchoninic acid assay (232235; Micro BCA ${ }^{\mathrm{TM}}$ Protein Assay kit; Thermo Fisher Scientific, Inc.). Heart protein extract ( $80 \mu \mathrm{g})$ was electrophoresed using a 5\% sodium dodecyl sulfate (SDS) polyacrylamide spacer gel $(60 \mathrm{~V} ; 30 \mathrm{~min})$ and a $12 \%$ SDS separation gel $(100 \mathrm{~V}$; $1.5 \mathrm{~h}$; both from Tiandz, Inc., Beijing, China), then transferred onto nitrocellulose membranes (Bio-Rad Laboratories, Inc., Hercules, CA, USA) by electrotransfer (200 mA; $1 \mathrm{~h}$ ). The membranes were washed four times in washing buffer [20 mM Tris base, pH 7.6; $12.5 \mathrm{mM} \mathrm{NaCl}$; and $0.5 \%$ Tween-20 (TBST buffer); Beijing Donglinchangsheng Biotechnology Co., Ltd., Beijing, China] then blocked with 5\% non-fat milk in Tris-buffered saline (20 mM Tris- $\mathrm{HCl}, \mathrm{pH} 7.6 ; 137 \mathrm{mM} \mathrm{NaCl}$ ) containing $0.1 \%$ Tween-20 (TBST) for $1 \mathrm{~h}$ at room temperature. Subsequently, the membranes were incubated with anti-rat monoclonal antibodies against HSP10 (1:2,000), HSP60 (1:20,000; ab13532; Abcam), and glyceraldehyde-3-phosphate dehydrogenase (GAPDH; 1:1,000; ab8224; Abcam) for $1 \mathrm{~h}$ at $37^{\circ} \mathrm{C}$. After washing with TBST, the membranes were incubated with peroxidase-conjugated secondary antibody (1:1,000; BA1038; Boster Systems, Inc., Pleasanton, CA, USA) at room temperature for $1 \mathrm{~h}$. Western blotting luminal reagent (Thermo Fisher Scientific, Inc.) was used to detect the antibody-antigen complexes. Bands on the developed film were quantified using Quantity One software, version 4.6.2 (Bio-Rad Laboratories, Inc.). The densities of the HSP60 and HSP10 protein bands were normalized against GAPDH.

Reverse transcription-quantitative polymerase chain reaction $(R T-q P C R)$. Total RNA was extracted from the heart tissues of the rats using the RNAiso Plus reagent (D9108A; Takara Biotechnology Co., Ltd., Dalian, China) according to the manufacturer's protocol. The optical density (OD) at $260 \mathrm{~nm}$ (OD260)/OD280 value of all the RNA samples was between 1.8 and 2.0, and the concentration of each RNA sample exceeded 1,000 ng/ $/ \mu \mathrm{l}$. RNA samples were reverse transcribed into cDNA using the PrimeScript RT Master Mix (DRR036A; Takara Biotechnology, Co., Ltd.), according to the manufacturer's protocol, and the reaction products were stored at $-80^{\circ} \mathrm{C}$ until further experimentation. cDNA samples $(2 \mu \mathrm{l})$ 
were suspended in a qPCR reaction system containing $10 \mu \mathrm{l}$ 2X SYBR Premix Ex Taq (DRR041S; Takara Biotechnology, Co., Ltd.), $0.6 \mu$ l each of the forward and reverse primers, and double-distilled water to a total volume of $20 \mu \mathrm{l}$. PCR primers were designed according to target mRNAs using Primer Premier software, version 5.0 (Premier Biosoft International, Palo Alto, CA, USA). The accession numbers of the mRNA sequences obtained from the GenBank database (www.ncbi. nlm.nih.gov/genbank/) were NM_012966.1, NM_022229.2 and NM_031144.3 for HSP10, HSP60 and $\beta$-actin, respectively. The primer sequences were as follows: $H S P 10(147 \mathrm{bp})$ forward, 5'-GAGTATTGGTTGAAAGGAGTG-3' and reverse, 5'-TGACAGGCTGAATCTCTCC-3'; HSP60 (128 bp) forward, 5'-CCGCCCCGCAGAAATGCTTCGA-3' and reverse, 5'-AGGCTCGAGCATCCGCACCAA-3'; and $\beta$-actin (110 bp) forward, 5'-TGCGCAAGTTAGGTTTTGTCA-3' and reverse, 5'-GCAGGAGTACGATGAGTCCG-3'. PCR was conducted using the Bio-Rad iQ5 Real-Time PCR Thermocycler (Bio-Rad Laboratories, Inc.), according to the manufacturer's protocol. Briefly, enzyme activation was performed at $95^{\circ} \mathrm{C}$ for $3 \mathrm{~min}$, followed by 40 cycles of denaturation at $95^{\circ} \mathrm{C}$ for $20 \mathrm{sec}$, annealing at $60^{\circ} \mathrm{C}$ for $30 \mathrm{sec}$, and elongation at $72^{\circ} \mathrm{C}$ for $30 \mathrm{sec}$. For each run, a negative control without cDNA was analyzed along with the experimental samples to ensure that there was no contaminating genomic DNA. A fourfold multiproportion dilution series of the cDNA was used in the qPCR reactions to obtain standard curves as follows: HSP10 mRNA slope $=-3.39$ and $r^{2}=0.995 ;$ HSP60 mRNA slope $=-3.43$ and $\mathrm{r}^{2}=0.998$; and $\beta$-actin mRNA slope $=-3.49$ and $\mathrm{r}^{2}=0.998$. The amplification efficiencies of the target and reference genes were approximately equal. Therefore, the HSP60 and HSP10 mRNA levels were normalized against $\beta$-actin mRNA levels using the $2^{-\Delta \Delta \mathrm{Cq}}$ method (27).

Statistical analysis. Differences between two groups were compared using one-way analysis of variance, followed by Fisher's Least Significant Difference and Duncan's new multiple range test, conducted using SPSS software, version 17.0 for Windows (SPSS, Inc., Chicago, IL, USA). Data are presented as the mean \pm standard deviation of at least three independent experiments. $\mathrm{P}<0.05$ was considered to indicate a statistically significant difference.

\section{Results}

Mortality of the rats during the heat stress period. After $20 \mathrm{~min}$ heat stress the rats began to exhibit signs of polypnea and nervousness (identified by signs of agitation). After $40 \mathrm{~min}$ heat stress, the rats were sweating and exhibited signs of thirst (identified by a high frequency of drinking water). After $60 \mathrm{~min}$ heat stress, a few of the rats were pronated, while after $100 \mathrm{~min}$ heat stress all the rats were pronated and appeared comatose, such that the experiment was terminated.

Enzyme activities and clinical symptoms of heat-stressed rats. The serum activities of CKMB and $\mathrm{LDH}$ exhibited similar patterns in the heat-stressed rats exposed to heat for various time periods (Figs. 1 and 2). The activities of LDH and CKMB were significantly decreased following $20 \mathrm{~min}$ heat stress, as compared with the control group $(\mathrm{P}<0.05)$; however,

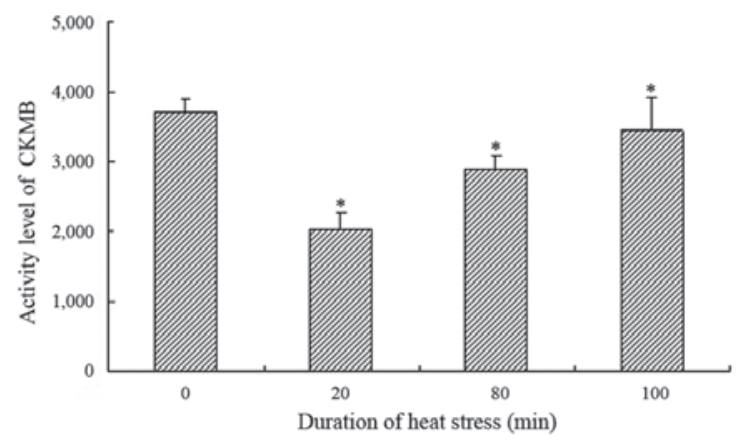

Figure 1. Alterations in the serum activity of CKMB in heat-stressed rats. Activity levels of CKMB showed an increasing trend with duration of heat stress exposure; however, enzyme levels were significantly lower at 20,80 and 100 min heat stress, as compared with the control group $(0 \mathrm{~min}) .{ }^{*} \mathrm{P}<0.05$ vs. the control group. Data are presented as the mean \pm standard deviation. CKMB, creatine kinase isoenzyme MB.

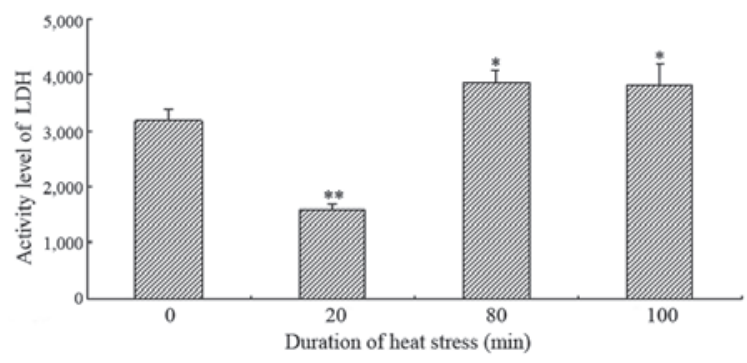

Figure 2. Alterations in serum activity of LDH in heat-stressed rats. Activity levels of LDH were decreased at $20 \mathrm{~min}$ heat exposure and then increased with time of exposure. ${ }^{*} \mathrm{P}<0.05$ and ${ }^{* * *} \mathrm{P}<0.01$ vs. the control group $(0 \mathrm{~min})$. Data are presented as the mean \pm standard deviation. LDH, lactate dehydrogenase

they showed an overall increasing trend with exposure time. The serum LDH activity was significantly increased after $80 \mathrm{~min}$ heat stress in the heat-stressed rats, as compared with the control group $(\mathrm{P}<0.05)$. Conversely, although the serum activity of CKMB showed the same increasing trend, the CKMB activity was significantly lower at 80 and $100 \mathrm{~min}$ heat stress, as compared with the control group.

Histopathological analyses. Heat stress-induced acute degeneration in the heart tissue of the heat-stressed rats was detected by histopathological analyses (Fig. 3). After $20 \mathrm{~min}$ heat stress, edema, which was characterized by increased interstitial spaces between the muscle fibers, a cloudy cytoplasm in swollen myocardial fibers and light hyperemia, was observed. After $80 \mathrm{~min}$ heat stress, granular degeneration, which was characterized by an enlarged cell size, a cloudy cytoplasm in myocardial fibers and obvious hyperemia in blood capillaries, was observed. Furthermore, after $100 \mathrm{~min}$ heat stress, necrosis, which was identified by karyolysis in the myocardial fibers, and obvious edema, were observed. Throughout the heat stress period, necrosis was occasionally observed.

Immunohistochemical analyses. Immunohistochemical analyses demonstrated that HSP60- and HSP10-positive signals were predominantly located in the cytoplasm of myocardial 
A

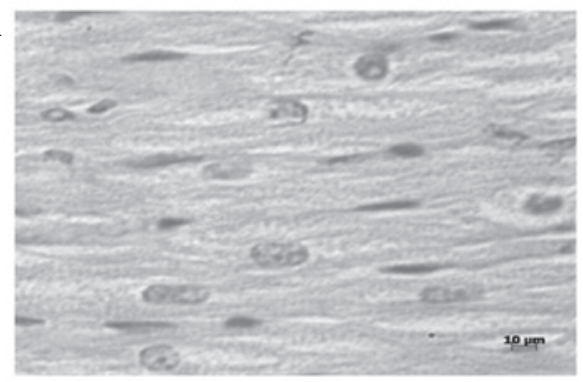

C

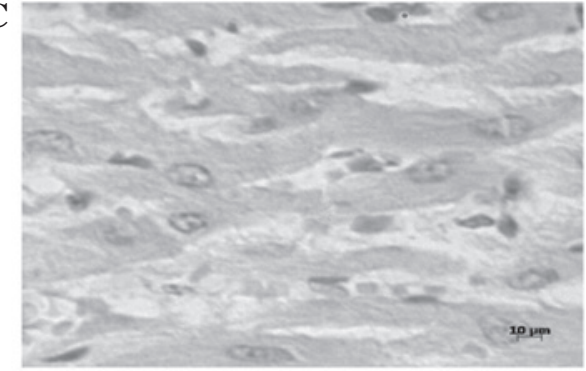

B

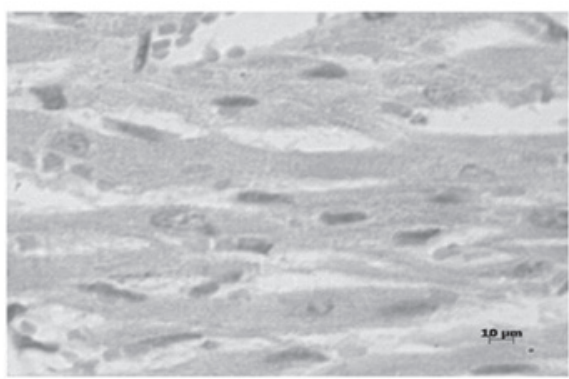

D

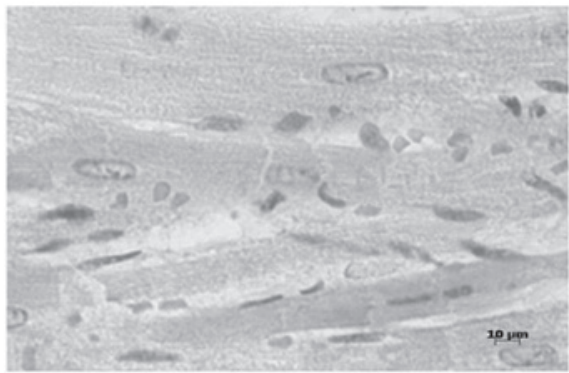

Figure 3. Heat-stressed myocardial cells underwent hematoxylin and eosin staining and were visualized using light microscopy (scale bar, $10 \mu \mathrm{m}$ ). (A) No obvious histopathological changes were observed in the myocardial cells of the control rats. (B) After 20 min heat stress, edema characterized by increased interstitial spaces between muscle fibers, a cloudy cytoplasm in swollen myocardial fibers and light hyperemia, was observed. (C) After 80 min heat stress, the cytoplasm of myocardial fibers appeared cloudy and eosinophilic and light hyperemia was observed. (D) After 100 min heat stress, necrosis of the enlarged myocardial fibers, characterized by karyolysis, was observed.
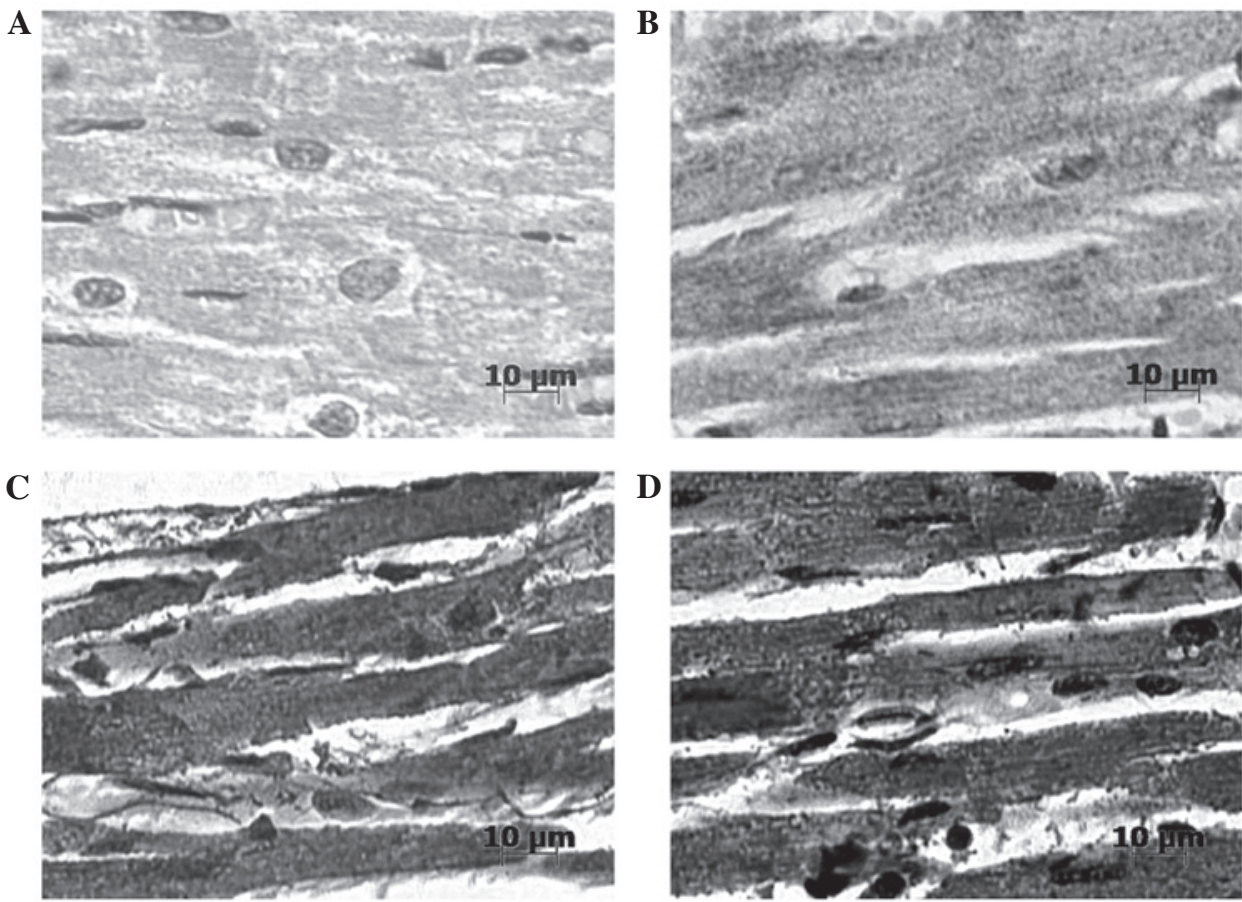

Figure 4. Localization of HSP60 and HSP10 in the heart tissue of heat-stressed rats was determined by immunostaining of rat myocardial cells (scale bar, $10 \mu \mathrm{m}$ ). (A) Prior to heat stress, HSP60 was not clearly detectable in the heart tissue of rats. (B) After 100 min heat stress, relatively strong positive signals of HSP60, exhibiting a punctiform distribution, were detected in the cytoplasm of the myocardial cells. (C) Prior to heat stress, HSP10 is strongly stained and was found to be predominantly located in the cytoplasm of myocardial cells. (D) After 100 min heat stress, immunoreactivity for HSP10 was present at significantly higher levels in the cytoplasm of the myocardial cells. HSP, heat shock protein.

cells (Fig. 4). Prior to heat stress, HSP60 was not clearly detectable in the heart tissue of rats. However, following $100 \mathrm{~min}$ heat stress, markedly stronger positive signals of HSP60, showing a punctiform distribution, were detected in the cytoplasm of the myocardial cells. Prior to heat stress, HSP10 staining was strongly positive and was predominantly located in the cytoplasm of myocardial cells. After $100 \mathrm{~min}$ heat stress, immunoreactive HSP10 was present at markedly higher levels in the cytoplasm of the myocardial cells.

HSP60 and HSP10 protein expression levels. The protein expression levels of HSP60 and HSP10 were detected in rat 


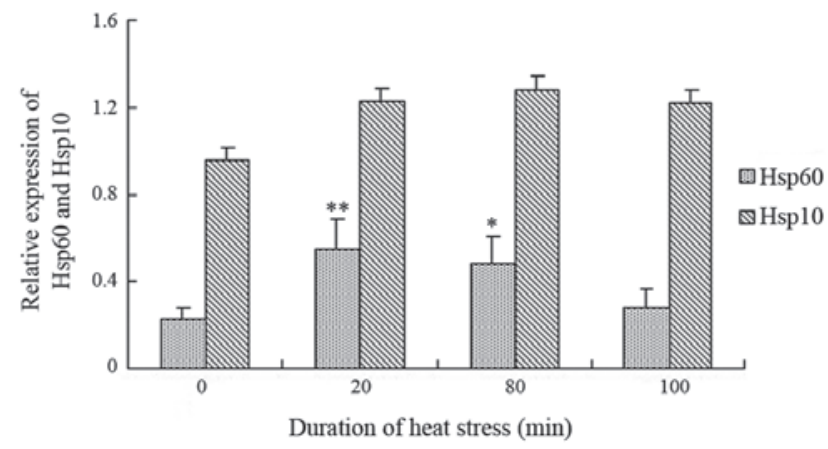

Figure 5. Relative protein expression of HSP60 and HSP10 in the heart tissues of heat-stressed rats were determined using western blotting. ${ }^{*} \mathrm{P}<0.05$ and ${ }^{* * *} \mathrm{P}<0.01$ vs. the control group $(0 \mathrm{~min})$. Data are presented as the mean $\pm \mathrm{stan}$ dard deviation. HSP, heat shock protein.

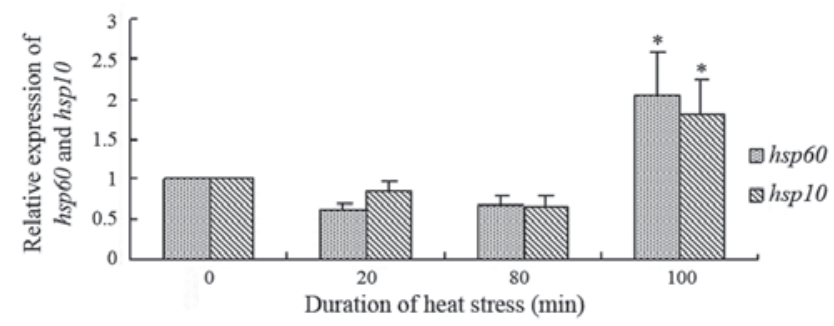

Figure 6. Relative mRNA expression levels of HSP60 and HSP10 in the heart tissues of heat-stressed rats were determined using reverse transcription-quantitative polymerase chain reaction. ${ }^{*} \mathrm{P}<0.05$ vs. the control group $(0 \mathrm{~min})$. Data are presented as the mean \pm standard deviation. HSP, heat shock protein.

heart tissues and were normalized against GAPDH (Fig. 5). After $20 \mathrm{~min}$ heat stress, the protein expression levels of HSP60 were significantly increased $(\mathrm{P}<0.01)$, and remained constant until 80 min heat stress $(\mathrm{P}<0.05)$, as compared with the control group. However, the protein expression levels of HSP60 returned to normal at $100 \mathrm{~min}$ heat stress. The protein expression levels of HSP10 exhibited a similar trend, although HSP10 was constitutively expressed under normal conditions and heat stress. The protein expression levels of HSP10 did not significantly alter in the heat-stressed rats; however, there was a slight increasing trend $(\mathrm{P}>0.05)$ from the beginning of heat stress.

HSP60 and HSP10 MRNA expression levels in the rat heart tissues. Fig. 6 presents the mRNA expression levels of HSP60 and HSP10, normalized against $\beta$-actin mRNA levels, in the heat-stressed heart tissues. Following 100 min heat stress, there were significant increases in the mRNA expression levels of HSP60 and HSP10, as compared with the control group $(\mathrm{P}<0.05)$. The mRNA expression levels of HSP10 in the heart tissue of the heat-stressed rats showed a similar trend to HSP6O.

\section{Discussion}

The results of serum enzyme (CKMB and LDH) assays are typically used as indexes of myocardial injury (28). A previous study demonstrated that the diversity of aspartate aminotransferase, $\mathrm{LDH}$ and $\mathrm{CK}$ often foreshadow heat shock-induced changes in cellular structure (29), and the activity of these enzymes in intercellular fluid has been associated with heart disease (30). Furthermore, these enzymes serve as molecular predictors of damage to cardiac muscle cells during heat stress (31). In the present study, the serum activities of LDH and CKMB were detected as indicators of heart damage under heat stress conditions, and an increasing trend with exposure to heat stress was observed. An elevation of plasma CKMB levels, which has been shown to be indicative of heart muscle damage, results from the disruption of the function and permeability of the muscle cell membrane (sarcolemma) (32). The activity of LDH has previously been evaluated as an indicator of stress during transportation, and a previous study reported acute cellular lesions in the hearts of transported pigs (33). This is consistent with the present study in which obvious lesions, characterized by granular and vascular degeneration and even necrosis, were observed in the heart tissue of heat-stressed rats using histopathological analyses. Furthermore, the activities of enzymes associated with myocardial cell damage were gradually increased with the duration of heat stress and reached statistical significance at $100 \mathrm{~min}$. Histopathological analyses revealed acute degeneration, including granular and vascular degeneration of myocardial cells; however, there was no obvious and extensive myocardial cell necrosis. These results suggested that acute degeneration may be sufficient to cause sudden death in animals during heat stress by disrupting the function and permeability of the myocardial cell membrane.

The distribution of HSPs may be associated with their protective function (34). In the present study, a higher density of HSP60-positive signals were detected in the heat-stressed groups, as compared with the control group, and strong positive signals of HSP10 that exhibited a punctiform distribution were detected in the cytoplasm of the heat-stressed myocardial cells. These results suggested that HSP60 and HSP10 were synthesized in response to heat stress. In addition, HSP60 and HSP10 exhibited a punctiform distribution in the mitochondria of heat-stressed cells. This was consistent with the results of a previous study, in which HSP60 was reported to be predominantly located in the cytoplasm and mitochondria of muscle fibers in humans (35). Furthermore, another study demonstrated that mammalian HSP60 was rapidly transported into the mitochondria following dehydration (36). Therefore, these molecules may be transported into the mitochondria under conditions of heat stress; however, further studies are required in order to confirm this.

In the present study, western blotting demonstrated that the protein expression levels of HSP60 were significantly increased following 20 and 80 min heat stress; thus suggesting that the elevation of HSPs in the heart may confer protection against stress-induced myocardial injury $(37,38)$. The protein expression levels of HSP60 were decreased following $100 \mathrm{~min}$ heat stress; however, the serum levels of HSP60 were high and histopathological analysis of the heat-stressed tissue revealed obvious lesions. In a previous study, HSP60 expression in the cytoplasm of myocardial cells was more prominent in intact areas than in degenerated areas (39). Concordantly, in the present study, HSP60 staining was markedly reduced in the cytoplasm of granular degenerated areas in myocardial cells. These results suggested that HSP60 may be considered a potential biomarker of heat stress-induced injuries of the 
heart. In the present study, the presence and localization of HSP60 and HSP10 in rat heart tissue in response to heat stress were evaluated. Although HSP60 and HSP10 should be functionally correlated, HSP10 was present in a higher number of specimens and had a higher expression level, as compared with HSP60; thus suggesting that HSP10 may have a different role in the heart tissue of rats. Similar results were reported in a recent study in which the HSP60 and HSP10 expression levels were investigated in a series of normal human bone marrows and within the cytoplasm of tumor cells (40). HSP10 was more obviously and constitutively expressed in unstressed myocardial cells under normal conditions, as compared with HSP60 in heat-stressed rats.

A previous study demonstrated that the expression levels of HSP60 and HSP1O were regulated simultaneously during carcinogenesis, since these genes are localized head-to-head on the chromosome (41). However, the quantitative relationship between the mRNA and protein expression levels of a gene has yet to be completely recognized. In the present study, the mRNA expression levels of HSP60 and HSP10 were gradually and significantly increased when the duration of heat stress was increased to $100 \mathrm{~min}(\mathrm{P}<0.05)$. The HSP60 protein expression levels were significantly increased following $20 \mathrm{~min}$ heat stress, but returned to normal at $100 \mathrm{~min}$, whereas HSP10 was constitutively expressed. These results suggested that HSP60 in myocardial tissue may be more susceptive to the effects of heat stress, as compared with HSP10 (42). HSP60 and HSP10 have previously been shown to form mitochondrial chaperone complexes that are believed to have a role in maintaining normal mitochondrial function (43). However, the detailed functions of these two HSPs in myocardial cells are yet to be fully elucidated.

\section{Acknowledgements}

The present study was supported by the National Key Basic Research program of China (973 program; grant no. 2014cB138502), the National Natural Science Foundation of China (grant no. 31372403), the National Department Public Benefit Research Foundation (agriculture; grant no. 201003060-11), the Priority Academic Program Development of Jiangsu Higher Education Institutions (PAPD), Jiangsu Province Plans to Graduate Research and Innovation Projects and the Sino-German Agricultural Cooperation Project of the Federal Ministry of Food, the Agriculture and Consumer Production.

\section{References}

1. Chen H, Adam A, Cheng Y, Tang S, Hartung J and Bao E: Localization and expression of heat shock protein 70 with rat myocardial cell damage induced by heat stress in vitro and in vivo. Mol Med Rep 11: 2276-2284, 2015.

2. Lee WC, Lin KY, Chiu YT, Lin JH, Cheng HC, Huang HC, Yang PC, Liu SK and Mao SJ: Substantial decrease of heat shock protein 90 in ventricular tissues of two sudden-death pigs with hypertrophic cardiomyopathy. FASEB J 10: 1198-1204, 1996.

3. Feder ME and Hofmann GE: Heat-shock proteins, molecular chaperones and the stress response: Evolutionary and ecological physiology. Annu Rev Physiol 61: 243-282, 1999.

4. Tissiéres A, Mitchell HK and Tracy UM: Protein synthesis in salivary glands of Drosophila melanogaster: Relation to chromosome puffs. J Mol Biol 84: 389-398, 1974.
5. Hartl FU: Molecular chaperones in cellular protein folding. Nature 381: 571-579, 1996.

6. Ryan MT and Pfanner N: Hsp70 proteins in protein translocation. Adv Protein Chem 59: 223-242, 2001.

7. Zhang L, Zhou R, Li X, Ursano RJ and Li H: Stress-induced change of mitochondria membrane potential regulated by genomic and non-genomic GR signaling: A possible mechanism for hippocampus atrophy in PTSD. Med Hypotheses 66: 1205-1208, 2006.

8. Hightower LE: Heat shock, stress proteins, chaperones and proteotoxicity. Cell 66: 191-197, 1991.

9. Glover JR and Lindquist S: Hsp104, Hsp70 and Hsp40: A novel chaperone system that rescues previously aggregated proteins. Cell 94: 73-82, 1998.

10. Richardson A, Schwager F, Landry SJ and Georgopoulos C: The importance of a mobile loop in regulating chaperonin/co-chaperonin interaction humans versus Escherichia coli. J Biol Chem 276: 4981-4987, 2001.

11. Hansen JJ, Bross P, Westergaard M, Nielsen MN, Eiberg H, Børglum AD, Mogensen J, Kristiansen K, Bolund L and Gregersen N: Genomic structure of the human mitochondrial chaperonin genes: HSP60 and HSP10 are localised head to head on chromosome 2 separated by a bidirectional promoter. Hum Genet 112: 71-77, 2003.

12. Damien P, Hemsley S and Canfield PJ: Association of uterine and salpingeal fibrosis with chlamydial hsp60 and hsp10 antigen-specific antibodies in chlamydia infected koalas. Clin Diagn Lab Immunol 12: 632-639, 2005.

13. Cappello F, Czarnecka AM, La Rocca G, Di Stefano A, Zummo G and Macario AJ: Hsp60 and Hsp10 as antitumor molecular agents. Cancer Biol Ther 6: 4, 2007.

14. Cappello F, David S, Rappa F, Bucchieri F, Marasà L, Bartolotta TE, Farina F and Zummo G: The expression of HSP60 and HSP10 in large bowel carcinomas with lymph node metastase. BMC Cancer 5: 139, 2005.

15. Pockley AG, Wu R, Lemne C, Kiessling R, de Faire U and Frostegård J: Circulating heat shock protein 60 is associated with early cardiovascular disease. Hypertension 36: 303-307, 2000.

16. Rizzo M, Cappello F, Marfil R, Nibali L, Gammazza AM, Rappa F, Bonaventura G, Galindo-Moreno P, O'Valle F, Zummo G, et al: Heat-shock protein $60 \mathrm{kDa}$ and atherogenic dyslipidemia in patients with untreated mild periodontitis: A pilot study. Cell Stress Chaperones 17: 399-407, 2012.

17. Yan J, Bao E and Yu J: Heat shock protein 60 expression in heart, liver and kidney of broilers exposed to high temperature. Res Vet Sci 86: 533-538, 2009.

18. Lin L, Kim SC, Wang Y, Gupta S, Davis B, Simon SI, Torre-Amione G and Knowlton AA: HSP60 in heart failure: Abnormal distribution and role in cardiac myocyte apoptosis. Am J Physiol Heart Circ Physiol 293: H2238-H2247, 2007.

19. Cappello F, Tripodo C, Farina F, Franco V and Zummo G: HSP10 selective preference for myeloid and megakaryocytic precursors in normal human bone marrow. Eur J Histochem 48: 261-266, 2004.

20. Corrao S, Campanella C, Anzalone R, Farina F, Zummo G, Conway de Macario E, Macario AJ, Cappello F and La Rocca G: Human Hsp10 and early pregnancy factor (EPF) and their relationship and involvement in cancer and immunity: Current knowledge and perspectives. Life Sci 86: 145-152, 2010.

21. Cappello F, Bellafiore M, David S, Anzalone R and Zummo G: Ten kilodalton heat shock protein (HSP10) is overexpressed during carcinogenesis of large bowel and uterine exocervix. Cancer Lett 196: 35-41, 2003.

22. Akyol S, Gercel-Taylor C, Reynolds LC and Taylor DD: HSP-10 in ovarian cancer: Expression and suppression of T-cell signaling. Gynecol Oncol 101: 481-486, 2006.

23. Shan YX, Liu TJ, Su HF, Samsamshariat A, Mestril R and Wang PH: Hsp10 and Hsp60 modulate Bcl-2 family and mitochondria apoptosis signaling induced by doxorubicin in cardiac muscle cells. J Mol Cell Cardiol 35: 1135-1143, 2003.

24. He Y, Shang X, Sun J, Zhang L, Zhao W, Tian Y, Cheng H and Zhou R: Gonadal apoptosis during sex reversal of the rice field eel: Implications for an evolutionarily conserved role of the molecular chaperone heat shock protein 10. J Exp Zool B Mol Dev Evol 314: 257-266, 2010.

25. Landry SJ, Steede NK and Maskos K: Temperature dependence of backbone dynamics in loops of human mitochondrial heat shock protein 10. Biochemistry 36: 10975-10986, 1997. 
26. Agnello D, Scanziani E, Di GM, Leoni F, Modena D, Mascagni P, Introna M, Ghezzi P and Villa P: Preventive administration of Mycobacterium tuberculosis 10-kDa heat shock protein (hsp10) suppresses adjuvant arthritis in Lewis rats. Int Immunopharmacol 2: 463-474, 2002.

27. Livak KJ and Schmittgen TD: Analysis of relative gene expression data using real-time quantitative PCR and the 2(-Delta Delta C(T)) Method. Methods 25: 402-408, 2001.

28. Bakay RA and Ward AA Jr: Enzymatic changes in serum and cerebrospinal fluid in neurological injury. J Neurosurg 58: 27-37, 1983.

29. Liu Z, Lv Y, Zhang M, Yue Z, Tang S, Islam A, Rehana B, Bao E and Hartung J: Hsp110 expression changes in rat primary myocardial cells exposed to heat stress in vitro. Genet Mol Res 11: 4728-4738, 2012.

30. Koelkebeck KW and Odom TW: Laying hen responses to acute heat stress and carbon dioxide supplementation: II. Changes in plasma enzymes, metabolites and electrolytes. Comp Biochem Physiol A Physiol 112: 119-122, 1995.

31. Haagensen L, Jensen D and Gesser H: Dependence of myosin-ATPase on structure bound creatine kinase in cardiac myofibrils from rainbow trout and freshwater turtle. Comp Biochem Phys A Mol Integr Physiol 150: 404-409, 2008.

32. Mitchell M and Sandercock D: Creatine kinase isoenzyme profiles in the plasma of the domestic fowl (Gallus domesticus): Effects of acute heat stress. Res Vet Sci 59: 30-34, 1995.

33. Zhu L, Bao E, Zhao R and Hartung J: Expression of heat shock protein 60 in the tissues of transported piglets. Cell Stress Chaperon 14: 61-69, 2009.

34. Georgopoulos $\mathrm{C}$ and Welch WJ: Role of the major heat shock proteins as molecular chaperones. Annu Rev Cell Biol 9: 601-634, 1993.
35. Kervinen H, Huittinen T, Vaarala O, Leinonen M, Saikku P, Manninen V and Mänttäri M: Antibodies to human heat shock protein 60 , hypertension and dyslipidemia. A study of joint effects on coronary risk. Atherosclerosis 169: 339-344, 2003.

36. Itoh $\mathrm{H}$, Komatsuda $\mathrm{A}$, Ohtani $\mathrm{H}$, Wakui H, Imai H, Sawada $\mathrm{K}$, Otaka M, Ogura M, Suzuki A and Hamada F: Mammalian HSP60 is quickly sorted into the mitochondria under conditions of dehydration. Eur J Biochem 269: 5931-5938, 2002.

37. Yu J, Bao E, Yan J and Lei L: Expression and localization of Hsps in the heart and blood vessel of heat-stressed broilers. Cell Stress Chaperon 13: 327-335, 2008.

38. Hutter JJ, Mestril R, Tam EK, Sievers RE, Dillmann WH and Wolfe CL: Overexpression of heat shock protein 72 in transgenic mice decreases infarct size in vivo. Circulation 94: 1408-1411, 1996.

39. Kervinen H, Huittinen T, Vaarala O, Leinonen M, Saikku P, Manninen V and Mänttäri M: Antibodies to human heat shock protein 60, hypertension and dyslipidemia. A study of joint effects on coronary risk. Atherosclerosis 169: 339-344, 2003.

40. Cappello F, David S, Rappa F, Bucchieri F, Marasà L Bartolotta TE, Farina F and Zummo G: The expression of HSP60 and HSP10 in large bowel carcinomas with lymph node metastase. BMC Cancer 5: 139, 2005.

41. Zhao Q, Wang J, Levichkin IV, Stasinopoulos S, Ryan MT and Hoogenraad NJ: A mitochondrial specific stress response in mammalian cells. EMBO J 21: 4411-4419, 2002.

42. Kim KK, Kim R and Kim SH: Crystal structure of a small heat-shock protein. Nature 394: 595-599, 1998

43. Lau S, Patnaik N, Sayen MR and Mestril R: Simultaneous overexpression of two stress proteins in rat cardiomyocytes and myogenic cells confers protection against ischemia-induced injury. Circulation 96: 2287-2294, 1997. 